\title{
Low-temperature catalytic conversion of carbonaceous materials
}

\author{
Roman B. Tabakaeva, Alexander V. Astafev, Alexander V. Kazakov, and Alexander S. Zavorin \\ National Research Tomsk Polytechnic University, 634050 Tomsk, Russia
}

\begin{abstract}
Laws of the rate of carbon conversion in steam atmosphere at a temperature in modes of the catalytic low-temperature treatment of peat, brown coal, semi-coke from peat and brown coal are obtained by experiments. Increasing of the rate of carbon conversion in temperature range up to $500{ }^{\circ} \mathrm{C}$ is achieved by using of catalysts. The possibility of using results is associated with the burners, a working zone of which is porous filling from carbonaceous particles.
\end{abstract}

\section{Introduction}

Gradual reduction of the reserves of primary energy - oil and gas, the steady rise of prices for their output are stimulated activation of research in the field of efficient use of alternative energy sources and low-grade sources [1].

The technologies of the steam thermal conversion of carbonaceous materials in admixture with catalytic additives in the temperature range up to $500^{\circ} \mathrm{C}$ were tested in order to involve of low-grade fuels for use in small power energy and autonomous power plants [2-6]. The basis of this technology is the steam oxidation of carbon component with producing of high-calorific gas mixture containing hydrogen, methane and carbon monoxide. The content of each component depends on the nature of source raw material, consumption and temperature of steam.

Burners of infrared radiation, which are based on the use of carbon filling in the working zone of combustion [7, 8], can be regarded as mini-heat generators, operating on the principle of lowtemperature conversion of carbon matrix upon steam delivery.

\section{The methodology and results of experiments}

Determination of the rate of carbon conversion depending on the steam temperature and consumption carried out in an experimental unit (Figure 1), providing control means of steam parameters and condition of the carbonaceous material, which allows to conducting qualitative and quantitative analysis in range of the object of carried researches.

Horizontal and vertical tube furnaces (accordingly 1,2) are installed in working position, reactor (3) with carbonaceous material was placed inside a horizontal tube furnace (1). Calorimetric bomb (4) was placed inside a vertical tube furnace (2), a certain amount of water was poured in bomb and then was transformed into saturated steam of predetermined temperature by heating. Control of the

a Corresponding author: TabakaevRB@tpu.ru 
overpressure of produced steam was carried out using a manometer (5). Steam consumption was changed by a valve (6) mounted on the steam-conductive pipe. The temperature of produced steam and steam-gas mixture after the reactor was measured by thermocouples (7). The formed steam-gas mixture after reaction steam with carbon of material which placed in the reactor was entered into the condenser (8) through steam-conductive pipe, and then pyrolysis condensate and conversion gases were turned in container through the pipe (9).

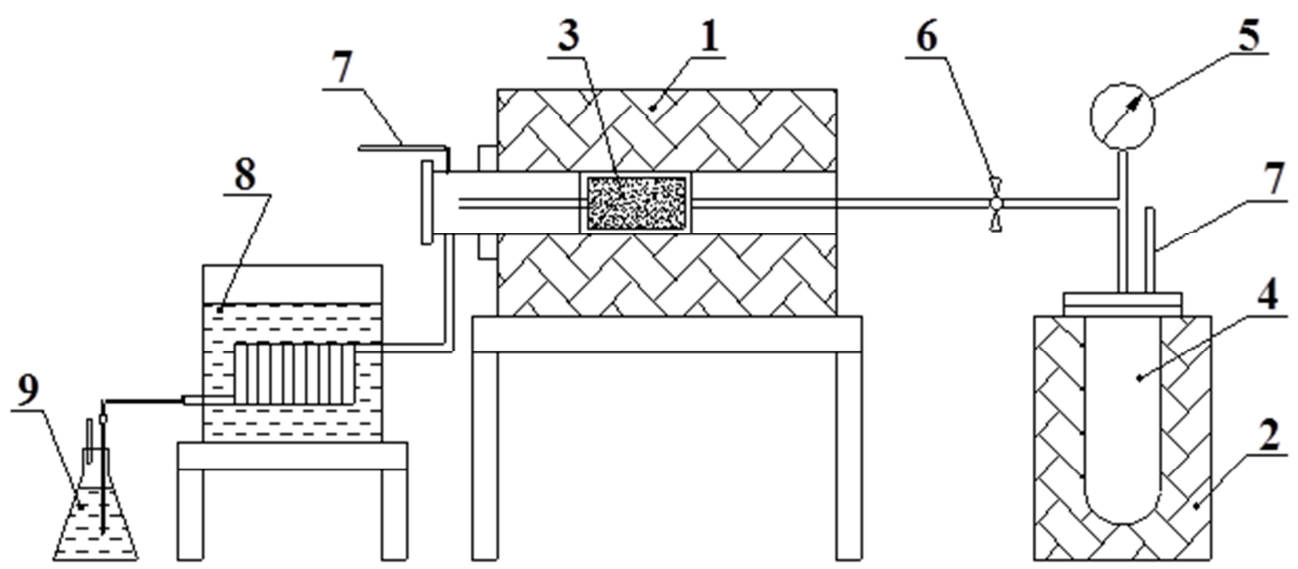

Figure 1. Scheme of experimental unit: 1 - horizontal tube furnace; 2 - vertical tube furnace; 3 - reactor; 4 - calorimetric bomb; 5 - manometer; 6 - valve of regulation; 7 - thermocouple; 8 - condenser; 9 - container for condensate and gas sampling.

Start and final mass of the carbonaceous material in the reactor were fixed, as well as the amount of formed condensate. The gas, produced by steam-heat conversion, was subjected to chromatographic analysis. The carbon content before and after experiment in tested material was determined by analyzer of elemental composition Vario Micro Cube, calibrated using reference samples.

Thermal conversion efficiency was evaluated according to the rate of carbon conversion to combustible gas:

$$
k=\frac{G_{1}-G_{2}}{G_{1}} \cdot 100, \%
$$

where $G_{1}$ и $G_{2}$ - start and final carbon mass in tested material.

Most experiments was performed on kriptol - a material with a high carbon content (95-98 \%) and developed pore structure, high gas permeability of which predetermined its use as a filling working substance in the previously developed burners [8]. The powdered hematite and soot iron were used as a catalytic additive.

Typical laws of the change of carbon conversion rate, which are result of experiments with kriptol, are presented in Figure 2. The figure shows that the most complete carbon conversion is achieved upon condition - the higher the temperature of the steam, the less the required consumption.

The generalized law, which may be used to select of the mode of steam-heat catalytic conversion on carbonaceous materials, was obtained as a result of the handing all experimental data (Figure 3). 
a) $\boldsymbol{k}_{c, \%}$

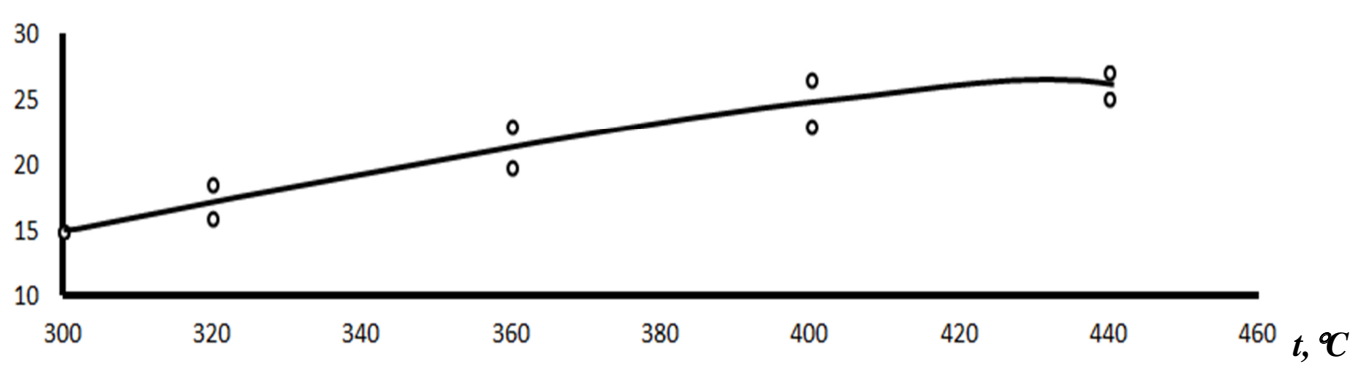

b) $\boldsymbol{k}_{\boldsymbol{c}, \%}$

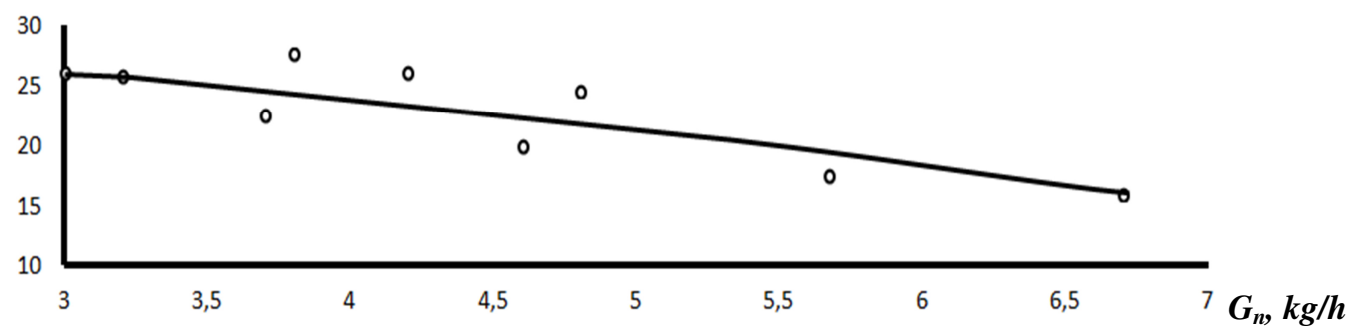

Figure 2. Law of the carbon conversion rate on temperature (a) and steam consumption (b): a - steam consumption $3 \mathrm{~kg} / \mathrm{h} ; \mathrm{b}$ - steam temperature $450^{\circ} \mathrm{C}$.

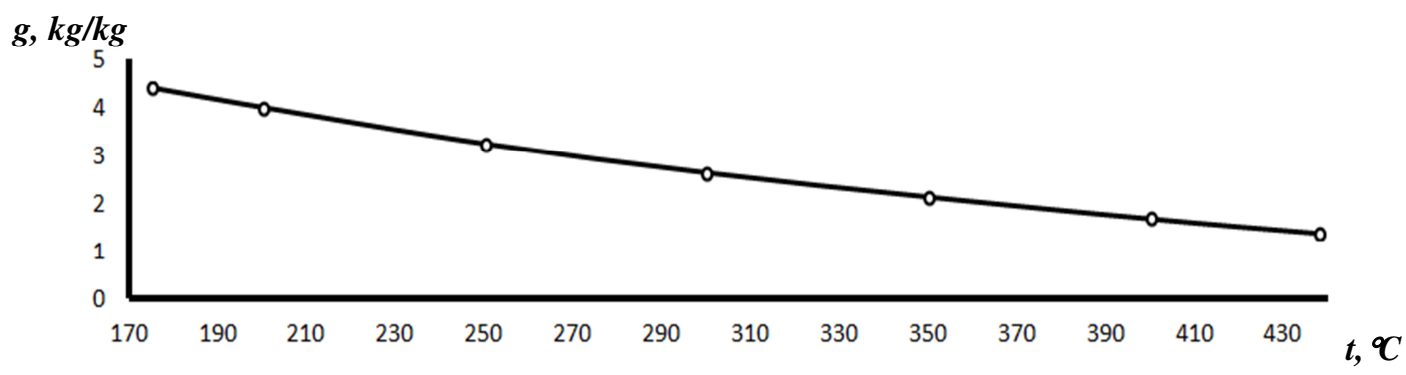

Figure 3. Specific steam consumption per $1 \mathrm{~kg}$ of carbon in depending of temperature.

The experiments on steam-heat conversion of peat, brown coal and semi-coke, produced by lowtemperature pyrolysis of this, were carried out under the same conditions.

The rate of carbon conversion this fuels was higher when entering catalyzing additives even with limit of the amount of incoming high-temperature steam (Table 1).

Table 1. The rate of carbon conversion on law-grade fuels

\begin{tabular}{|l|c|c|c|c|}
\hline Mode Material & Peat & Brown Coal & Semi-coke from peat & Semi-coke from brown coal \\
\hline With additives & 78.4 & 74.4 & 12.6 & 11.8 \\
\hline Without additives & 45.6 & 44.9 & 0.0 & 0.0 \\
\hline
\end{tabular}

The composition of the combustible components in produced gas significantly changes by introduced catalyzing additives into a carbonaceous material. The concentration of hydrogen in produced gas at additive conversion increases in 2-3 times due to the decomposition of steam, which introduced into the process. The concentration of methane increases 1.2-1.5 times due to consecutive reactions with carbon monoxide, as evidenced by its concentration decrease. 


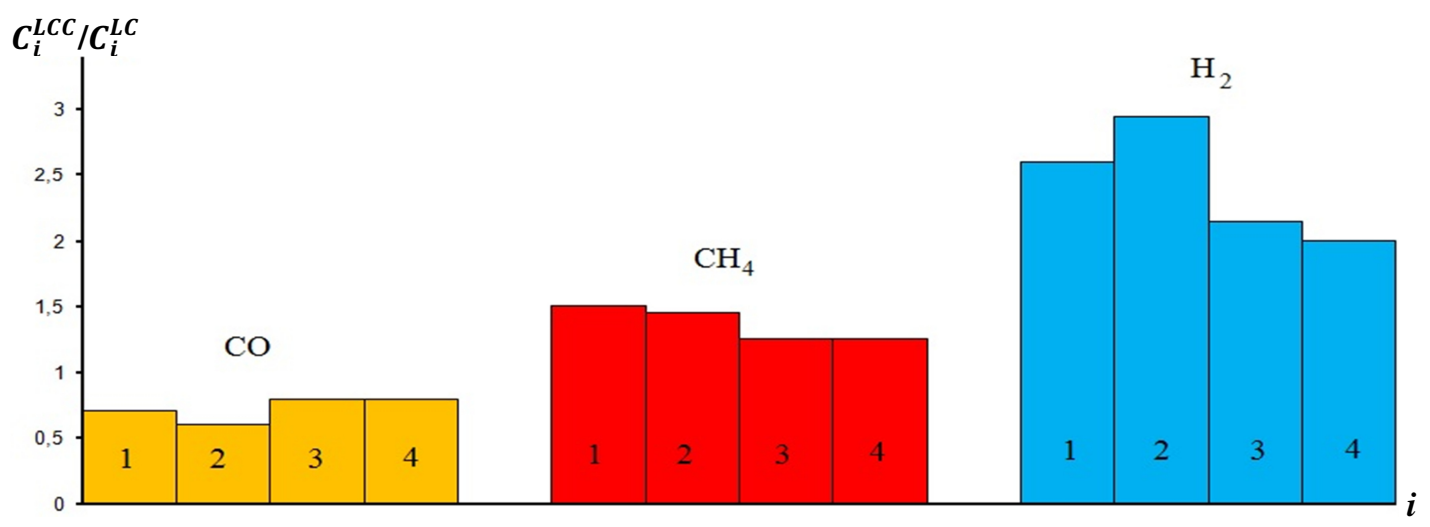

Figure 4. The ratio of the gas components concentrations at conversion of solid fuels in experiments with catalyst additives $\left(C_{i}^{L C C}\right)$ and without additives $\left(C_{i}^{L C}\right): 1$ - peat; 2 - brown coal; 3 - semi-coke from peat; 4 - semi-coke from brown coal.

\section{Conclusion}

Thus, quantitative conversion parameters of the mixture of available carbonaceous powdered materials with catalytic additives during heating to $500{ }^{\circ} \mathrm{C}$ in conditions of steam supply are established. The results showed a perspective of the implementation this technology in burners of flameless combustion using carbonaceous materials (kriptol, semi-coke from peat and brown coal) as a porous filling of working zone.

The reported study was partially supported by the Ministry of education and science of The Russian Federation, state order No. 2069 (2.1322.2014).

\section{References}

1. N. Abas, A. Kalair, N. Khan, Futures 69, 31 (2015)

2. A.V. Kazakov, R.B. Tabakaev, P.Y. Novoseltsev, A.V. Astafev, MATEC Web of Conferences 19, 01014 (2014)

3. A.S. Zavorin, R.B. Tabakaev, P.Y. Novoseltsev, A.V. Astafev, MATEC Web of Conferences 19, 01015 (2014)

4. A.S. Zavorin, A.V. Kazakov, A.A. Makeev, S.V. Podorov, Thermal Engineering 57, 77 (2010)

5. R.B. Tabakaev, P.S. Gergelizhiu, A.V. Kazakov, A.S. Zavorin, IOP Conference Series: Materials Science and Engineering 66, 012052 (2014).

6. A.V. Kazakov, T.M. Plakhova, R.I. Popov, MATEC Web of Conferences 19, 01019 (2014)

7. P.S. Gergelizhiu, S.A. Khaustov, R.B. Tabakaev, P.U. Novoseltsev, A.V. Kazakov, A.S. Zavorin, in Proceedings of 2014 International Conference on Mechanical Engineering, Automation and Control Systems (MEACS 2014), 2014, 6986901

8. R.A. Visloguzov, R.B. Tabakaev, A.S. Zavorin, S.V. Dolgov, K.I. Klochko, in Proceedings of 2014 International Conference on Mechanical Engineering, Automation and Control Systems (MEACS 2014), 2014, 6986943 